\title{
Time-of-flight secondary ion mass spectrometry analysis of chitosan-treated viscose fibres
}

\author{
Matjaž Finšgar ${ }^{\mathrm{a}, *}$, Tijana Ristić ${ }^{\mathrm{b}}$, Pedro Fardim ${ }^{\mathrm{c}}$, Lidija Fras Zemljičc ${ }^{\mathrm{d}, * *}$

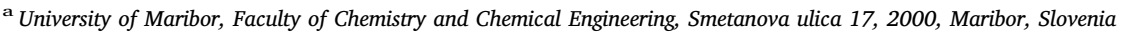 \\ ${ }^{\mathrm{b}}$ Health Care Department, Tosama d.o.o., Production of Medical Supplies, Vir, Šaranovičeva cesta 35, 1230, Domžale, Slovenia \\ ${ }^{\mathrm{c}}$ Laboratory of Fibre and Cellulose, Åbo Akademi University, 20500, Turku, Finland \\ ${ }^{\mathrm{d}}$ University of Maribor, Faculty of Mechanical Engineering, SI-2000, Maribor, Smetanova Ulica 17, Slovenia
}

A R T I C L E I N F O

\section{Keywords:}

TOF-SIMS

Secondary ion mass spectrometry

Surface analysis

Chitosan

Nanoparticles

Cellulose

\begin{abstract}
A B S T R A C T
Time-of-flight secondary ion mass spectrometry (ToF-SIMS) was employed to analyse cellulose viscose fibres treated with different chitosan-based solutions. The analysis reports several new features in the TOF-SIMS spectra for systems with various forms of chitosan-treated surfaces. The characteristic positive ion TOF-SIMS signals for chitosan are reported at $\mathrm{m} / \mathrm{z}$ 147.90, 207.07, and 221.09, and characteristic signals for trimethyl chitosan are present at $\mathrm{m} / \mathrm{z} 58.03$ and 102.09. Furthermore, new fragments were suggested to characterise acetylated chitosan molecules. The relative surface concentrations of different species were obtained based on the specific signal ratios (originating from a specific fragment and cellulose). SIMS imaging was then performed in order to investigate the surface distribution of chitosan, trimethyl chitosan, and Na-containing nanoparticles. In order to perform TOF-SIMS imaging, the above-mentioned characteristic signals were employed and $\mathrm{m} / \mathrm{z}$ 22.99 was used for Na nanoparticles.
\end{abstract}

\section{Introduction}

Natural cellulose-based fibres are increasingly gaining attention in the engineering of composite materials with a special emphasis on their antimicrobial properties. Viscose rayon is a fibre made of partially depolymerised cellulose from woody material by successive treatment with $\mathrm{CS}_{2}, \mathrm{NaOH}$, and $\mathrm{H}_{2} \mathrm{SO}_{4}$ resulting in shorter and softer fibres that are more suitable for biomedical applications [1-3]. Regarding the surface modification of cellulose fibres to introduce antimicrobial properties, natural bioactive compounds are deemed to be the most attractive, eco-friendly alternative to synthetic antimicrobial agents. The latter is especially important for applications in cosmetics, medicine, and health care, as these types of materials need to be safe, nontoxic, and skin friendly $[1,2,4]$.

Among the various bioactive compounds, cationic polysacharrides show promise in biomedical applications due to their antimicrobial activity. One of the most popular amino polysaccharides is chitosan, which is obtained by alkaline deacetylation of chitin. Chitosan's positive charge, the degree of $\mathrm{N}$-deacetylation, the mean polymerisation degree, and the nature of the chemical modifications are the properties that strongly influence its antimicrobial effectiveness [1,2,4]. It is used as a natural antimicrobial agent for the development of new medical products and is gaining in popularity as the FDA has approved it as a food ingredient. Besides its antimicrobial activity, it exhibits anti-cholesterolemic, anti-ulcer, anti-uremic, and anti-tumour effects [5]. A wide variety of chitosan derivatives are synthesised due to the limited solubility of commercial chitosan. Among the most promising ones are quarternised chitosan, carboxymethylated chitosan, and tiol-chitosan, which have found applications as matrixes for the preparation of several medical materials in different forms and for different purposes [6]. Chitosan has already been extensively studied as an active surface agent integrated into textile fibres to produce advanced sanitary products and medical devices $[1,2,4]$. The latest trend is to design chitosan nanoparticles that can be reversibly or irreversibly attached onto cellulose material. The high specific area due to their nano size as well as the manipulation of the bonding may increase the bioactive properties of fibres functionalised by chitosan nanoparticles $[7,8]$. It was shown in our previous work that chitosan nanoparticles have a high antibacterial function with important applications, e.g. as viscose tampon coatings that inhibit the pathogens causing toxic vaginal infections. It has also been shown that chitosan nanoparticles attached onto viscose fibres may also act as a novel vaginal drug delivery system for local

\footnotetext{
* Corresponding author.

** Corresponding author.

E-mail addresses: matjaz.finsgar@um.si (M. Finšgar), lidija.fras@um.si (L.F. Zemljič).
} 
Table 1

Characteristic fragments for specific compounds.

\begin{tabular}{ll}
\hline compound & $m / z$ signal \\
\hline $\mathrm{C}_{6} \mathrm{H}_{7} \mathrm{O}_{3}{ }^{+}$(hexose monomer) & $127.04,145.05$ \\
ethylene glycol monostrearate & $283.26\left(-\mathrm{CH}_{2} \mathrm{CH}_{2} \mathrm{OH}\right)$ and $311.30(-\mathrm{OH})$ \\
different hydrocarbons separated by & $675,659,631,615,587,571,543,527$, \\
$\quad m / z 16$ or 28 & $499,483,455,437$, and 387 \\
$\mathrm{CH}_{4} \mathrm{~N}^{+}$ & 30.03 \\
$\mathrm{Na}^{+}$ & 22.99 \\
$\mathrm{NH}_{4}{ }^{+}$ & 18.03 \\
from chitosan & \\
$\mathrm{C}_{4} \mathrm{H}_{21} \mathrm{~N}_{14} \mathrm{O}$ (from chitosan) $\rightarrow$ & $281.20 \rightarrow 283.22$ \\
$\quad \mathrm{C}_{4} \mathrm{H}_{23} \mathrm{~N}_{14} \mathrm{O}$ (from chitosan) & \\
acetylated chitosan & 221.09 and 207.07 \\
$\mathrm{C}_{8} \mathrm{H}_{13} \mathrm{NO}_{5}$ chitin monomer from & 203.08 \\
$\quad$ chitosan & 179.08 \\
$\mathrm{C}_{6} \mathrm{H}_{13} \mathrm{NO}_{5}$ glucosamine fragment from & \\
$\quad$ chitosan & 161.07 \\
$\mathrm{C}_{6} \mathrm{H}_{11} \mathrm{NO}_{4}$ glucosamine fragment from & \\
$\quad$ chitosan & 147.90 \\
chitosan fragment & 144.07 \\
$\mathrm{C}_{6} \mathrm{H}_{10} \mathrm{NO}_{3}{ }^{+}$(from the glucosamine & \\
monomer) & 102.09 \\
$\mathrm{C}_{5} \mathrm{H}_{12} \mathrm{NO}^{+}$from trimethylchitosan & 59.07 \\
$\mathrm{C}_{3} \mathrm{H}_{9} \mathrm{~N}^{+}$from trimethylchitosan & 58.03 \\
$\mathrm{C}_{2} \mathrm{H}_{4} \mathrm{NO}^{+}$from chitosan & \\
\hline
\end{tabular}

administration of microbiocids or other therapeutic drugs/vaccines [7]. Due to their beneficial bioactive properties, chitosan in different structural forms also has implications for modifying and testing many other medical devices (vascular grafts, catheters, wound dressings, hernia meshes, etc.) and material surfaces, due to which its use as a functional coating is of crucial importance [5].

The success of cellulose functionalisation and applications, especially in the case of medical textiles, depends strongly on their surface properties; i.e. the physics and chemistry of the fibre/fabric surface strongly influence their interaction with the chosen environment. The surface of antimicrobial functionalised fibres is responsible for the interaction with microorganisms, thus, the development and optimisation of many functional medical textiles require detailed knowledge of the chemical and physical microstructure of the surface. This knowledge plays a central role in understanding process - surface structure property relationships, which are crucial parameters in the enhancement or suppression of the efficiency of functionalised fibres regarding bacteria and fungi inhibition. It should be noted that the bonding mechanism of coatings with correlations in surface chemistry changes and the further influence of surface parameters on medical device surface bio-efficiency are not yet clearly or fully understood. Thus, besides developing novel multifunctional natural coatings for cellulose fibres, achieving a deep understanding of the surface composition of functionalised fibres is also a great challenge.

Time-of-flight secondary ion mass spectrometry (ToF-SIMS) is a surface-sensitive analytical method. It is a powerful technique for analysing and directly mapping chemical components on the surfaces of solid samples [9-15]. In combination with a ToF analyser, ToF-SIMS provides several advantages compared with other mass spectrometric and surface-sensitive techniques. For example, a wide mass range can be analysed (0-10000 atomic mass units); it has a high mass to charge ratio $(m / z)$ resolution $>10000$, and it is possible to reconstruct any image area in order to obtain information about a specific fragment [16-23].

Hitherto, to the best of our knowledge, no TOF-SIMS analysis of viscose fibres functionalised by chitosan and chitosan nanoparticle has been reported. Furthermore, herein, new SIMS fragments are reported to characterise specific components.

\section{Experimental}

Viscose fibres functionalised by chitosan and chitosan nanoparticles adsorbed onto viscose fibres at variable $\mathrm{pH}$ values were analysed by the ToF-SIMS technique. In this research, chitosan (CS) and trimethyl chitosan (TMC) nanoparticle dispersions were used as cellulose fibre coatings and compared with CS solutions coated on the fibre. Chitosan adsorption (in solution and nanoparticle form) onto fibres was performed at $\mathrm{pH}$ values of 4 and 7 in order to investigate the influence of different $\mathrm{pH}$ values on chitosan macromolecule conformation and, consequently, on its adsorption ability.

\section{Materials}

CS $(M=82000 \mathrm{~g} / \mathrm{mol}$, degree of deacetylation $77.4 \%)$ and TMC ( $M=90000 \mathrm{~g} / \mathrm{mol}$, degree of trimethylation $66 \%$ ) were supplied by Kitozyme, Herstal, Belgium. Chitosan powder was suspended in ultrapure water (with a resistivity of $18.2 \mathrm{M} \Omega$, obtained from Milli-Q, Millipore Corporation, Massachusetts, USA) in order to prepare $0.5 \%$ $(w / V)$ solution. The solution was stirred continuously while lactic acid (concentrated) was added dropwise to enable the dissolution of chitosan. Afterwards, the solution was left stirring overnight and the $\mathrm{pH}$ was adjusted with lactic acid to 4.0 prior to further usage.

Dissolution of TMC was achieved by suspending TMC powder in ultrapure water. The solution was left stirring overnight. Since TMC is water-soluble, lactic acid was added only to adjust the $\mathrm{pH}$ to 4.0. The $\mathrm{pH}$ value of both CS and TMC solutions was also adjusted to 7 (with $0.1 \mathrm{M} \mathrm{NaOH}$ ) before being applied as a fibre coating. The same preparation procedure has been employed previously [7,24].

Chitosan nanoparticles were prepared by the ionic gelation

Table 2

Sample preparation with corresponding abbreviations.

\begin{tabular}{|c|c|}
\hline Sample abbreviation & Description \\
\hline $\mathrm{CV}$ & Viscose fibres (without CS treatment - untreated sample, cellulose base). \\
\hline CS-R4 & $\begin{array}{l}\mathrm{CV} \text { treated with } 0.5 \%(\mathrm{w} / \mathrm{v}) \mathrm{CS} \text { solution at } \mathrm{pH} 4 \text {; medical grade } \mathrm{CS} \text { was used with } M=82000 \mathrm{~g} / \mathrm{mol} \text {, degree of deacetylation }-\mathrm{DDA}=77.6 \% \text {; the } \mathrm{pH} \text { was } \\
\text { adjusted with concentrated lactic acid. }\end{array}$ \\
\hline CS-R7 & CV treated with $0.5 \%(\mathrm{w} / \mathrm{v}) \mathrm{CS}$ solution at $\mathrm{pH} 7$; medical grade $\mathrm{CS}, M=82000 \mathrm{~g} / \mathrm{mol}$, DDA $=77.6 \%$; the $\mathrm{pH}$ was adjusted with $0.1 \mathrm{M}$ NaOH solution. \\
\hline CSNP4 & $\begin{array}{l}\text { CV treated with chitosan nanoparticles (CSNP) dispersion, synthesised by ionic gelation between CS and sodium tripolyphosphate using a mass ratio of 5:1 } \\
\text { (CS:TPP); the pH of the CSNP dispersion was } 4 \text { (adjusted with concentrated lactic acid). }\end{array}$ \\
\hline CSNP7 & $\begin{array}{l}\text { CV treated with CSNP, synthesised by ionic gelation between CS and sodium tripolyphosphate using a mass ratio of 5:1 (CS:TPP); the pH of the CSNP } \\
\text { dispersion was } 7 \text { (adjusted with } 0.1 \mathrm{M} \mathrm{NaOH)} \text {. }\end{array}$ \\
\hline TMC-R4 & $\begin{array}{l}\text { CV treated with } 0.5 \%(\mathrm{w} / \mathrm{v}) \text { TMC solution, } \mathrm{pH} 4 \text {; medical grade TMC, } M=90000 \mathrm{~g} / \mathrm{mol} \text {, degree of substitution }-\mathrm{DS}=64 \% \text {; the } \mathrm{pH} \text { was adjusted with } \\
\text { concentrated lactic acid. }\end{array}$ \\
\hline TMC-R7 & $\begin{array}{l}\text { CV treated with TMC solution, } c=0.5 \%(\mathrm{w} / \mathrm{v}) \text {, } \mathrm{pH} 7 \text {; medical grade TMC, } M=90000 \mathrm{~g} / \mathrm{mol} \text {, degree of substitution }-\mathrm{DS}=64 \% \text {; the } \mathrm{pH} \text { was adjusted with } \\
0.1 \mathrm{M} \mathrm{NaOH} \text { solution. }\end{array}$ \\
\hline TMCNP4 & $\begin{array}{l}\text { CV treated with a trimethyl chitosan nanoparticle (TMCNP) dispersion at pH 4; particles were synthesised using TPP with a 5:1 TMC:TPP mass ratio; the } \\
\text { pH was adjusted with concentrated lactic acid. }\end{array}$ \\
\hline TMCNP7 & $\begin{array}{l}\text { CV treated with a trimethyl chitosan nanoparticle (TMCNP) dispersion at pH 7; particles were synthesised using TPP with a 5:1 TMC:TPP mass ratio; the } \\
\text { pH was adjusted with } 0.1 \mathrm{M} \mathrm{NaOH} \text {. }\end{array}$ \\
\hline
\end{tabular}


<smiles>CC(=O)NC(C(C)=O)C(O)C(O)CO</smiles>

$\mathrm{N}$-acetylglucosamine<smiles>COC1C(CO)OC(C)C([N+](C)(C)C)C1O</smiles>

trimethyl chitosan<smiles>NC1C(O)OC(CO)C(O)C1O</smiles>

glucosamine

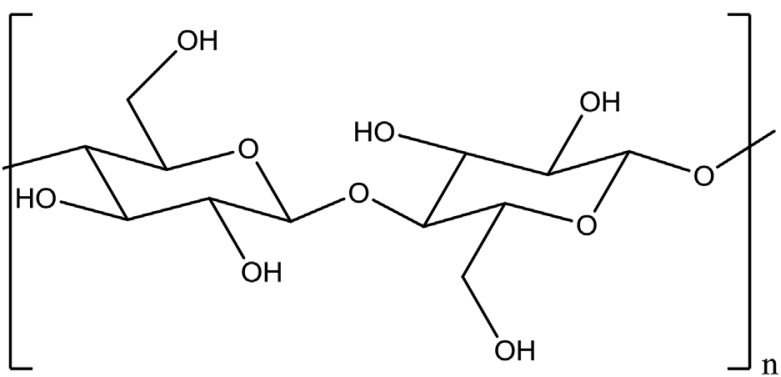

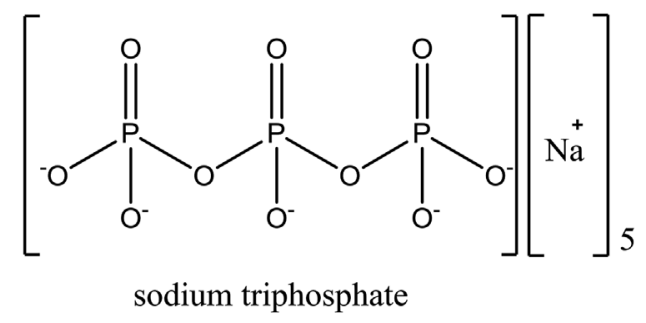

cellulose

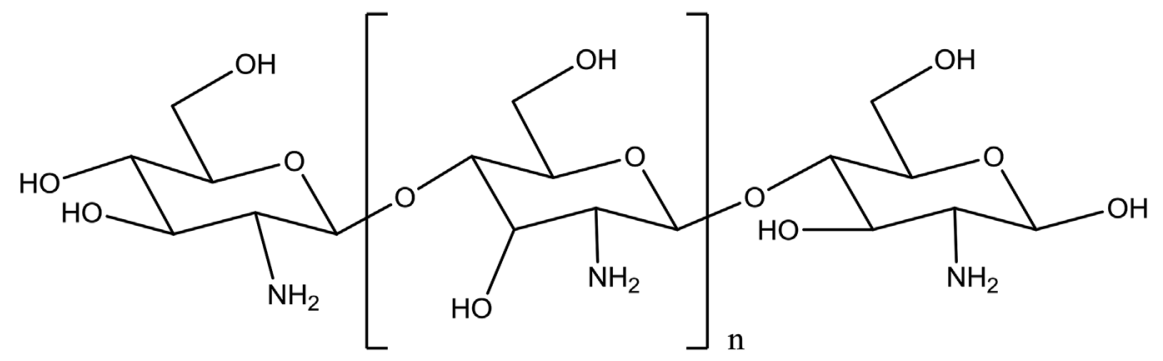

chitosan

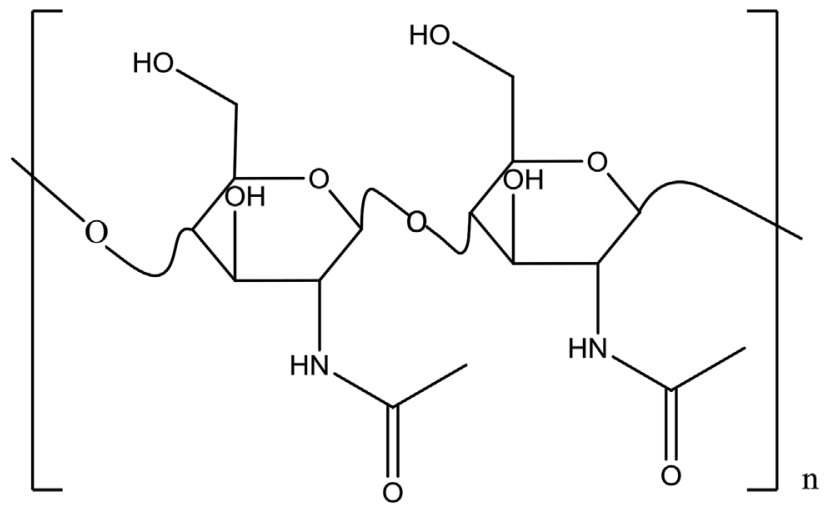

chitin

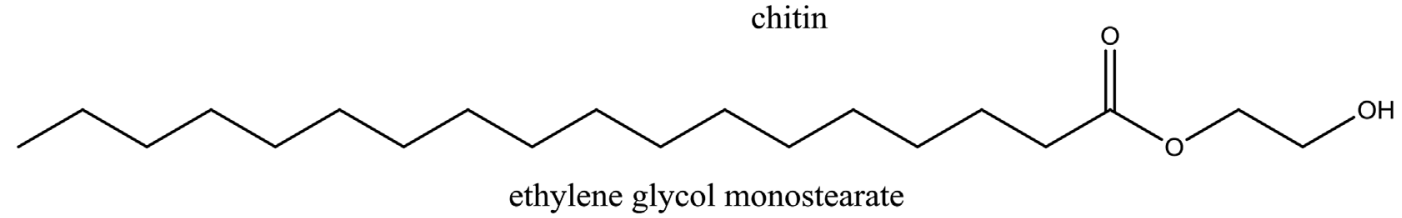

Fig. 1. Structures of the different components analysed with ToF-SIMS.

technique, as discussed in detail previously [7,25]. Regenerated cellulose fibres, pure and highly absorbent, in the form of a tampon band composed of two types of fibres, Lenzing Viscose and Lenzing Viscostar , mixed at a $70-30 \%$ ratio, were chosen as a base material for the adsorption of chitosan solutions and chitosan nanoparticle dispersions. 


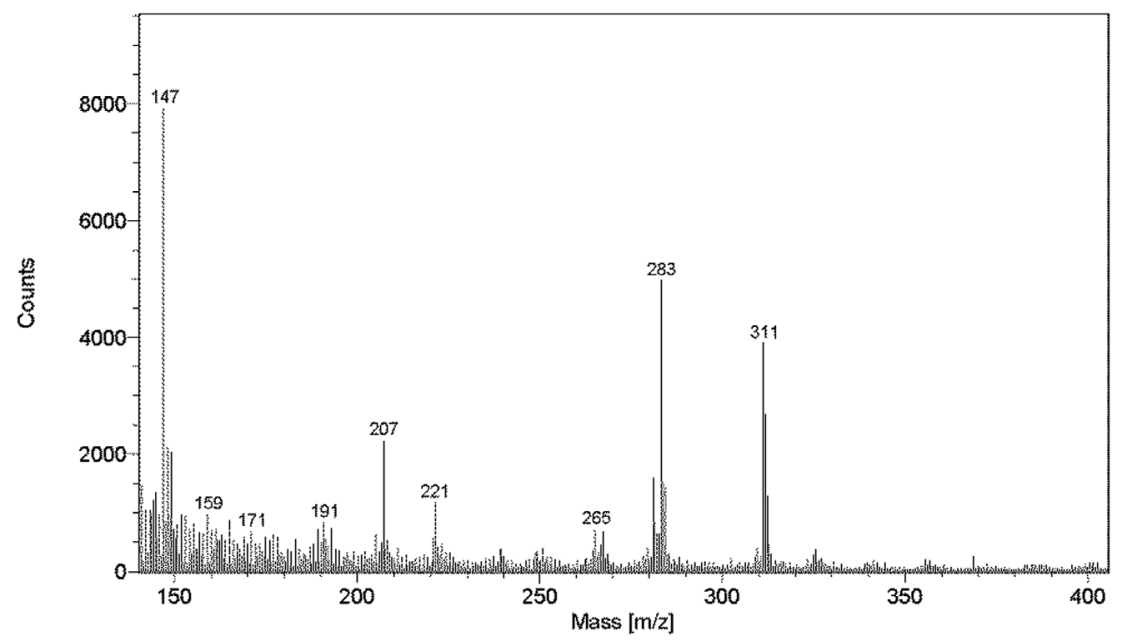

Fig. 2. The positive ion ToF-SIMS spectrum in the $m / z$ range of $140-400$ measured for the CS-R4 sample.

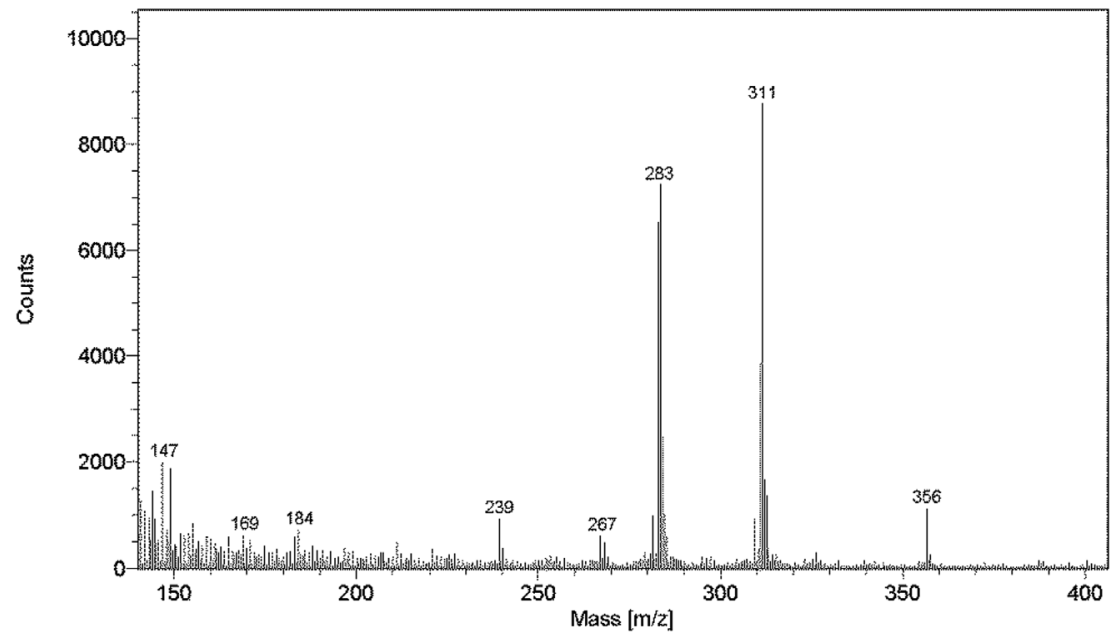

Fig. 3. The positive ion ToF-SIMS spectrum in the $m / z$ range of $140-400$ measured for the CS-R7 sample.

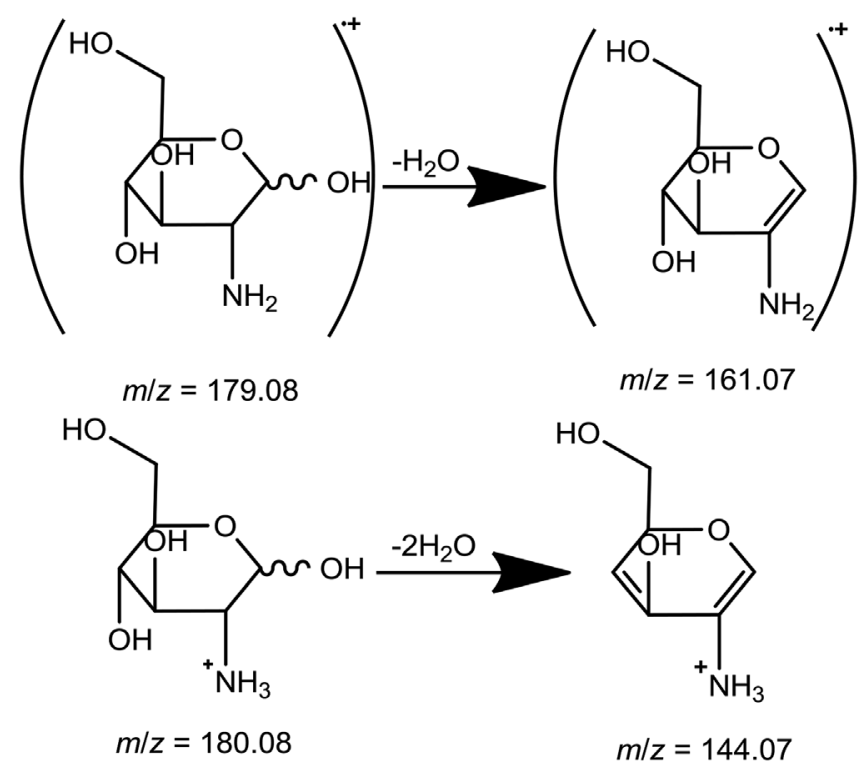

Fig. 4. Suggested fragmentation of glucosamine [35].
Functionalisation of viscose cellulose fibres

Fibres were treated by aqueous CS solutions or nanoparticle dispersion by an impregnation procedure. Impregnation was carried out at room temperature for a period of $30 \mathrm{~min}$ at a wet pickup of $80-100 \%$ with the help of a two-roller foulard (pressure 2 bar, passage of the material $2 \mathrm{~m} / \mathrm{min}$ ). Samples were dried at $40{ }^{\circ} \mathrm{C}$ for $30 \mathrm{~min}$ in a laboratory oven. The fibres were subsequently conditioned before being analysed further [7,24].

Different coating procedures resulted in 8 differently treated fibre samples, whose designations are presented in Table 2 (an untreated reference sample is also included).

\section{ToF-SIMS technique}

Secondary ion mass spectra were acquired using a Physical Eletronics ToF-SIMS TRIFT II spectrometer equipped with a primary ion gun that produces a beam of ${ }^{69} \mathrm{Ga}^{+}$ion source. Measurements were performed at an acceleration voltage of $25 \mathrm{kV}$ for $7 \mathrm{~min}$, in positive ion mode. Spectra were collected in the $\mathrm{m} / \mathrm{z}$ ratio range between 2 and 4000. At least three different areas were analysed on each sample in order to check for reproducibility, and representative spectra were reported. Charge compensation was performed with an electron flood gun pulsed out of phase with respect to the ion gun. The spectra were calibrated using the hydrocarbon fragments $\mathrm{CH}^{+}, \mathrm{C}_{2} \mathrm{H}_{3}{ }^{+}, \mathrm{C}_{3} \mathrm{H}_{5}{ }^{+}$, and 

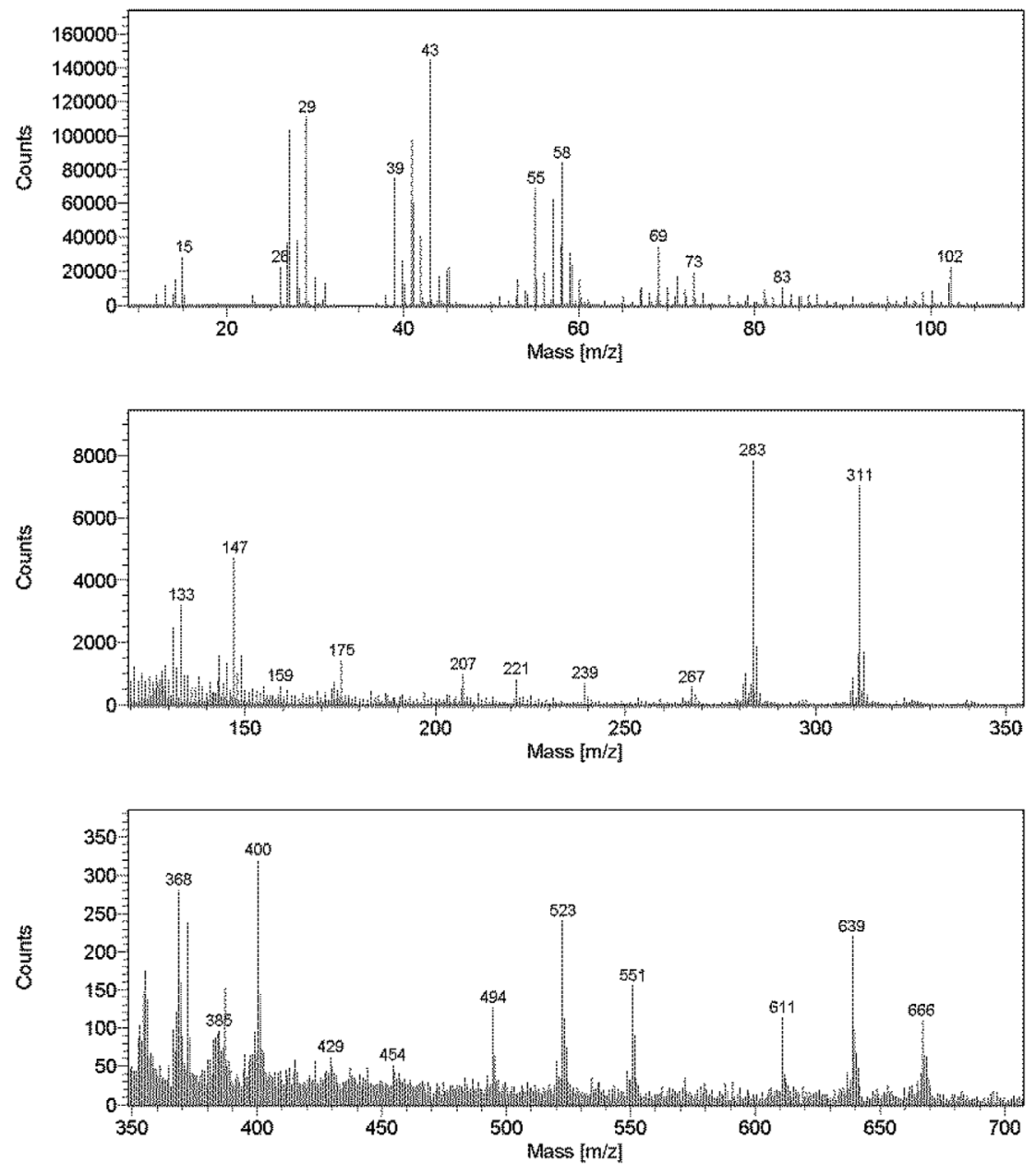

Fig. 5. The positive ion ToF-SIMS spectrum ( $m / z$ range $10-700$ ) for the TMC-R7 sample.

Table 3

The signal intensity ratios of the mass peak at $m / z 147.90,102.09$, or 58.03 relative to the mass peak at $m / z 127.04$ (the standard deviations calculated from 3 measurements are given in brackets).

\begin{tabular}{llll}
\hline Sample & $\begin{array}{l}147.90 / 127.04 \\
\text { (counts/counts) }\end{array}$ & $\begin{array}{l}102.09 / 127.04 \\
\text { (counts/counts) }\end{array}$ & $\begin{array}{l}58.03 / 127.04 \\
\text { (counts/counts) }\end{array}$ \\
\hline CV & $0.38(0.01)$ & $0.37(0.10)$ & $3.09(1.20)$ \\
CS-R4 & $4.00(1.98)$ & & \\
CS-R7 & $0.77(0.14)$ & & \\
CSNP4 & $0.76(0.50)$ & & \\
CSNP7 & $0.60(0.14)$ & $17.89(1.44)$ & $60.08(6.29)$ \\
TMC-R4 & & $23.60(2.13)$ & $74.91(13.3)$ \\
TMC-R7 & & $5.15(0.86)$ & $16.78(3.28)$ \\
TMCNP4 & & $25.02(5.52)$ & $81.45(13.99)$ \\
TMCNP7 & & & \\
\hline
\end{tabular}

$\mathrm{C}_{7} \mathrm{H}_{7}{ }^{+}$. The mass resolution $(m / \Delta m)$ of the SIMS instrument was approx. 10000 .

\section{Results and discussion}

\section{Description of the untreated viscose fibres}

Table 1 and Fig. 1 summarise the characteristic signals that were obtained and the components investigated in this study. The characteristic $m / z$ peaks of the hexose monomer at $m / z 127.04\left(\mathrm{C}_{6} \mathrm{H}_{7} \mathrm{O}_{3}{ }^{+}\right)$ and $145.05\left(\mathrm{C}_{6} \mathrm{H}_{9} \mathrm{O}_{4}{ }^{+}\right)$were detected for the $\mathrm{CV}$ sample (untreated viscous fibres - used as a reference). However, these signals were not intense - with a relative intensity (rel. int.) of $15 \%$ and $17 \%$, respectively (the spectrum is not shown herein). Moreover, mass peaks at $m / z$ 283 (a group of signals at $m / z 281,282,283,284$, and 285) and at $m / z$ 311 (a group of signals at $m / z 309,310,311,312$, and 313) were also present in the spectrum for the CV sample. They most likely originate from ethylene glycol monostearate [26,27], which is an additive for a viscose formulation. In the high $\mathrm{m} / \mathrm{z}$ region (above 350 ), intense mass peaks that would describe cellulose were not detected (due to intense fragmentation).

Furthermore, intense peaks separated by 16 or $28 \mathrm{~m} / z$ units were detected at $m / z 675 \rightarrow m / z 659 \rightarrow m / z 631 \rightarrow m / z 615 \rightarrow m / z 587 \rightarrow m /$ $z 571 \rightarrow m / z 543 \rightarrow m / z 527 \rightarrow m / z 499 \rightarrow m / z 483$ (a fragment at $m / z$ 481 was also detected) $\rightarrow m / z 455 \rightarrow m / z \quad 437 \rightarrow m / z$ 387. Masses separated by 16 or $28 \mathrm{~m} / z$ units, as present for the latter case, indicate cleavages of hydrocarbon fragments $\mathrm{CH}_{3}$ or $\mathrm{C}_{2} \mathrm{H}_{4}$ (a minor deviation from the 16 or 28 units indicates the presence of other fragment isotopes). The occurrence of hydrocarbons on the viscous fibres is most likely due to surface contamination by some long-chain polymers on top of the viscose polymer. The probable origin of contamination is due to the viscose spinning process, where surfactants and lubricants are added [26]. It is also possible that adventitious carbon species adsorbed on the surface after the sample preparation procedure and transferred to the spectrometer $[28,29]$, although this surface contamination does not usually have such a high molecular mass.

CS solution-treated samples (CS-R4 and CS-R7)

The purpose of this analysis is to demonstrate that CS was adsorbed 
CS-R4 sample
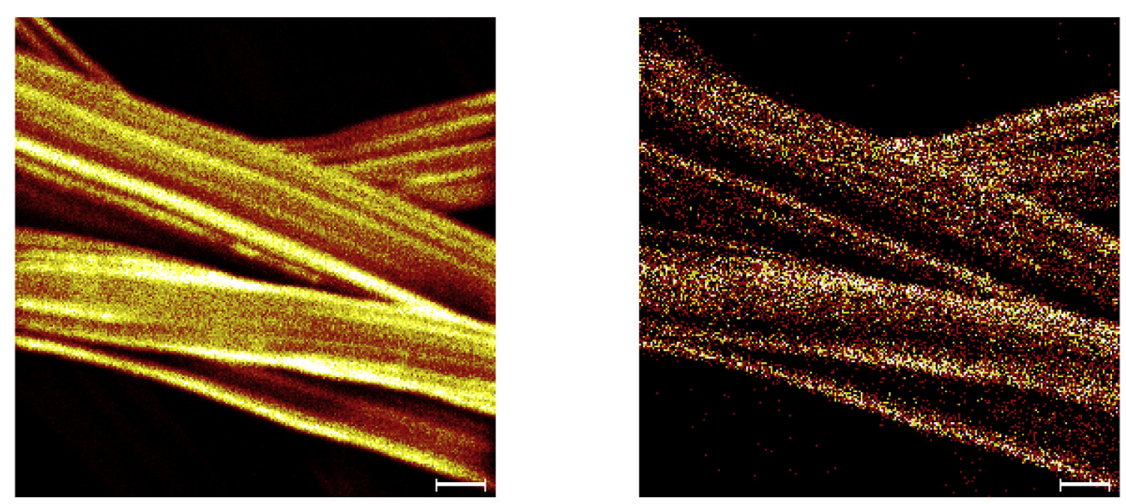

CS-R7 sample
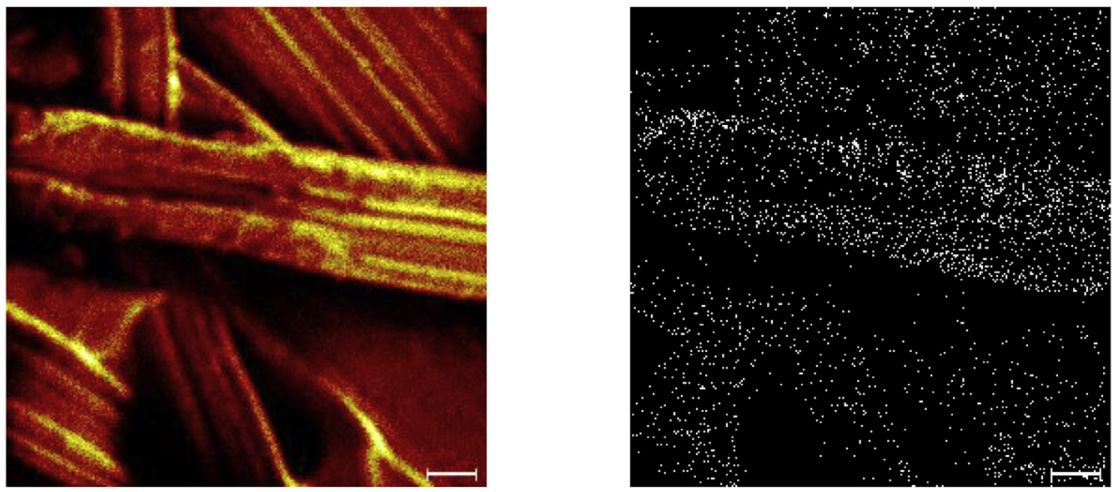

CSNP4 sample
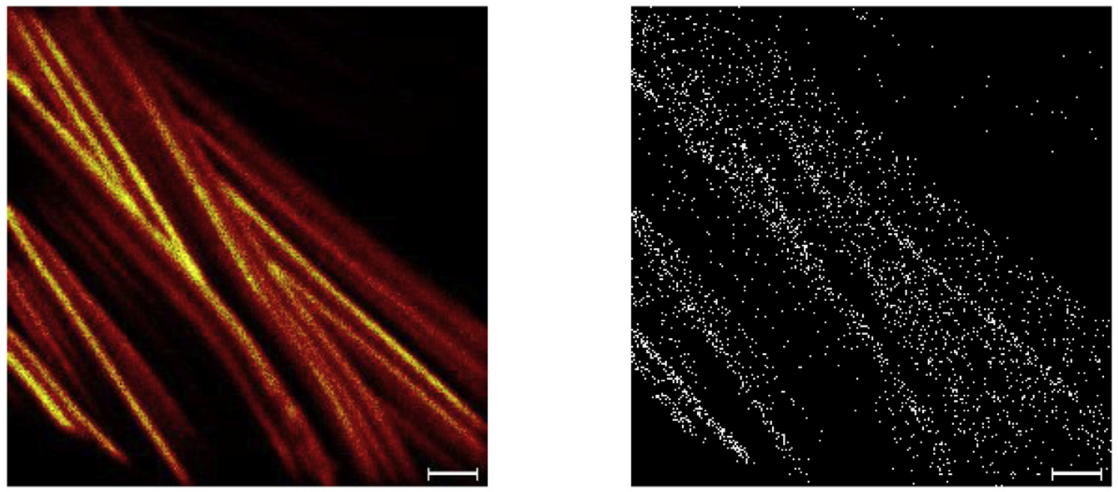

\section{CSNP7 sample}
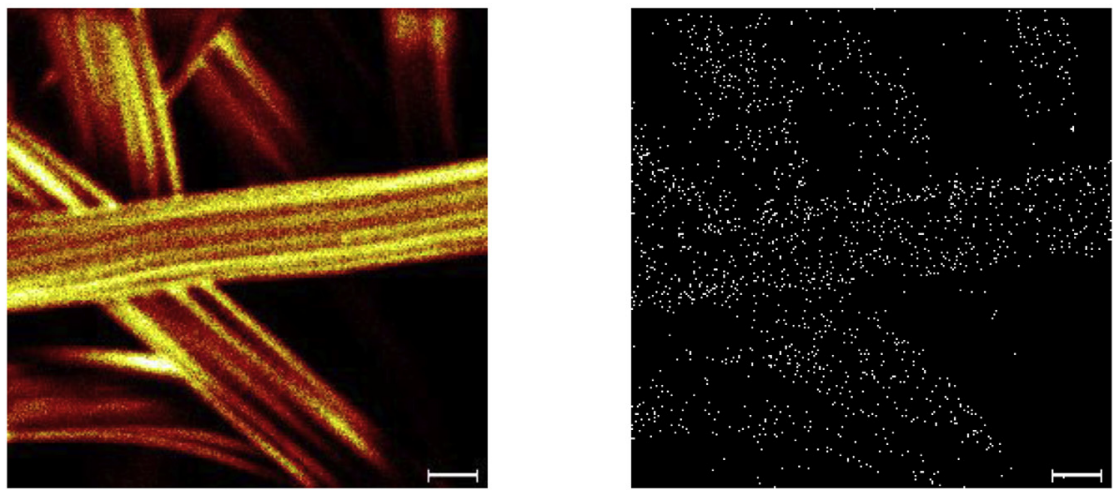


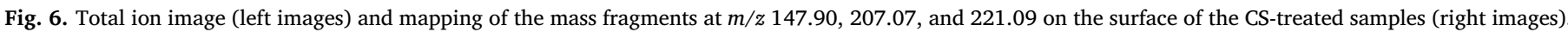
The scale bar is $10 \mu \mathrm{m}$.

on the CV sample from the CS-containing solutions at $\mathrm{pH} 4$ and 7. Moreover, the influence of different $\mathrm{pH}$ values on $\mathrm{CS}$ macromolecule conformation and, consequently, on its adsorption ability, was investigated. As both samples were treated with $C S$, peaks at $m / z 18.03$ and $m / z 30.03$ are expected due to $\mathrm{NH}_{4}{ }^{+}$and $\mathrm{CH}_{4} \mathrm{~N}^{+}$fragments [30], respectively. However, for both CS-R4 and CS-R7 these peaks had low intensity - the rel. ints. were $13 \%$ and $15 \%$ for the $m / z 18.03$ signal and $14 \%$ and $16 \%$ for the $m / z 30.03$ signal, respectively.

Figs. 2 and 3 show a characteristic segment of the positive ion ToFSIMS spectra measured for CS-R4 sample. The low $m / z$ region did not differ significantly from the spectrum of the reference $\mathrm{CV}$ viscose fibres as the same base material was employed. In the higher $m / z$ region, the CS-R4 sample spectrum shows intense peaks at $m / z$ 147.90, 207.07, 221.09, 281.20 and 283.22. The signals at $\mathrm{m} / \mathrm{z} 207.07$ and 221.09 most likely originate from acetylated CS [30,31] (the fragments $\mathrm{C}_{7} \mathrm{H}_{13} \mathrm{NO}_{6}$ and $\mathrm{C}_{8} \mathrm{H}_{15} \mathrm{NO}_{6}$ originate from acetylglucosamine due to acetylated chitosan). The fragment at $m / z 281.20$ has been ascribed previously to $\mathrm{C}_{4} \mathrm{H}_{21} \mathrm{~N}_{14} \mathrm{O}$, which originates from CS [30-33]. However, how this fragment is formed from CS is currently not clear. A peak at $m / z 147$ was also reported previously to be characteristic of chitosan [30,34]. The peak at $m / z 281.20$ was detected in the spectrum of the CS-R4 and CS-R7 samples as a part of a strong group of relatively broad peaks around $m / z 283$ (the highest peak was at $m / z 283.22$, rel. int. 62\%), which could represent a group of the same molecular fragments composed of different isotopes. However, the peak at $m / z 283$, together with the signal at $m / z 311$, could also originate from ethylene glycol monostrearate in the base viscose fibre, as explained above. This peak pair (at $m / z 283$ and 311) was detected with an intense signal (always with the rel. int. above 50\%, apart from TMC, for which it was lower than 6\%) in all the measured samples, including the CV reference, as mentioned above.

The fragmentation of CS or acetylated CS using ToF-SIMS has not been studied or published in detail yet. Possible fragments built from the glucosamine monomer or chitin monomer could be speculated. A peak at $m / z 144.07$ was detected (but was not intense, with a rel. int. of $15 \%$ ), possibly originating from $\mathrm{C}_{6} \mathrm{H}_{10} \mathrm{NO}_{3}{ }^{+}$(from the glucosamine monomer after the cleavage of two $-\mathrm{OH}$ groups [35]). On the other hand, signals referring to glucosamine fragments from deacetylated CS, i.e. $\mathrm{C}_{6} \mathrm{H}_{13} \mathrm{NO}_{5}$ at $m / z 179.08$ or $\mathrm{C}_{6} \mathrm{H}_{11} \mathrm{NO}_{4}$ at $m / z 161.07$ were detected, but at relatively low intensity (rel. ints. $3-10 \%$ ). It is assumed that the peak at $m / z 161.07$ could be formed from glucosamine by the cleavage of $-\mathrm{OH}$ [36]. The suggested fragmentations to obtain $\mathrm{m} / \mathrm{z}$ signals at 144.07 and 161.7 from glucosamine are given in Fig. 4 (these fragments were proposed previously using the electron impact ionisation source [35]). This is additional new information compared with the previous ToF-SIMS analysis for CS, where only acetylglucosamine, and not glucosamine fragments, was reported [30]. Furthermore, the degree of deacetylation was $77.6 \%$ (Table 2); therefore, mass peaks originating from acetylated chitin are also expected and, therefore, the occurrence of chitin monomers $\left(\mathrm{C}_{8} \mathrm{H}_{13} \mathrm{NO}_{5}\right)$ was investigated. The nominal mass of this monomer is $203 \mathrm{~g} / \mathrm{mol}$. However, the peak at $\mathrm{m} / \mathrm{z} 203.08 \mathrm{had}$ low rel. ints. (3-5\%) for both CS-treated samples.

Differences were detected when comparing the spectra for the sample prepared at pH 4 (CS-R4 sample, Fig. 2) with that at pH 7 (CSR7 sample, Fig. 3). The residual Na resulting from the $\mathrm{pH}$ adjustment was confirmed for the latter, as a peak of moderate intensity at $m / z$ 22.99 was present. This signal was not detected in the CS-R4 spectrum. Peaks for the CS-R7 sample spectrum at $m / z$ 147.90, 207.07, and 221.09 were less intense compared with the spectrum for the CS-R4 sample. This implies that the treatment at $\mathrm{pH} 4$ resulted in a higher amount of CS on the viscose fibre surfaces compared with the treatment at $\mathrm{pH}$ 7. Additionally, for the CS-R7 sample, a peak with a rel. int. of
$17 \%$ at $m / z 356$ was present. This peak was not detected for the CS-R4 or for the reference CV sample. The origin of that peak remains unknown.

In general, the $m / z$ region above 400 showed more peaks in the spectrum for the CS-R7 sample than for the CS-R4 sample. This might be explained by the fact that the surface contaminants on the base viscose fibre were removed more effectively in the more acidic solution $(\mathrm{pH} 4)$, but retained on the fibres treated at neutral $\mathrm{pH}$ (similarly as for the untreated sample, as explained in Section 3.1).

\section{Chitosan nanoparticle-treated samples (CSNP4 and CSNP7)}

For both CSNP4 and CSNP7, a signal was detected at $m / z 22.99$, which is ascribed to the presence of Na on the surface. As this peak was present for both samples (treatment in solutions with $\mathrm{pH} 4$ and 7), it most likely originates from sodium tripolyphosphate (part of the sample). The Na signal was more intense for CSNP4 compared to CSNP7.

The same as found above for CS-R4 and CS-R7, peaks at $m / z 147.90$, 207.07, and 221.09 were detected for both CSNP4 and CSNP7. These signals were less intense for the nanoparticles compared with the signals in the spectra for S-R4 and CS-R7; however, their presence again demonstrates that CS is attached to the surface. Part of the spectrum in the high mass region ( $m / z 250-900)$ was similar for both nanoparticletreated samples, indicating that the surface contamination with highmolecular mass substances was similar at both $\mathrm{pH}$ values. In general, for both samples the positive ion ToF-SIMS spectra were similar, and no significant differences between the samples can be detected by TOFSIMS.

\section{Trimethyl chitosan solution-treated samples (TMC-R4 and TMC-R7)}

The positive ion ToF-SIMS spectrum of TMC-R7 is given in Fig. 5 . The peaks representing CS fragments were detected at $m / z 58.03$, $102.09,147.90,207.07$, and 221.09. Also, the presence of the suspected contamination peaks at $m / z 283$ and 311 (described above) were still present.

In the ionisation procedure, a $\mathrm{C}_{3} \mathrm{H}_{9} \mathrm{~N}^{+}$fragment (with a nominal mass of $59 \mathrm{~g} / \mathrm{mol}$ ) is expected to form from the TMC samples [32]. In fact, the peak at $m / z 59.07$ for TMC-R7 was present in Fig. 5. Compared to that peak, an even more intense peak is observed at $m / z 58.03$, probably originating from $\mathrm{C}_{2} \mathrm{H}_{4} \mathrm{NO}^{+}$[32]. The peak at $\mathrm{m} / z 102.09$ in the spectrum (Fig. 5) possibly originates from $\mathrm{C}_{5} \mathrm{H}_{12} \mathrm{NO}^{+}$, which could be formed from TMC, (however, to the best of our knowledge, this fragment has not been reported previously for TMC-treated samples). A signal with a rel. int. of $3 \%$ at $m / z 22.99$ was measured for the TMC-R7 sample, but was missing for the TMC-R4 sample. The presence of this $\mathrm{Na}$ signal most likely arises due to the $\mathrm{pH}$ adjustment with $\mathrm{NaOH}$ solution in the case of TMC-R7. As suggested above, the peaks at $m / z$ 147.90, 207.07, and 221.09 represent CS, and these peaks were also detected for the TMC-R4 and TMC-R7 samples. These peaks were more intense for the TMC-R7 sample compared to the TMC-R4 sample (as shown above for the CS-treated solutions, this was the opposite of the higher intensities for CS-R7 compared to CS-R4).

In the high $m / z$ region (above 350), peaks appeared at the same $m /$ $z$, but the signals had higher intensities for TMC-R7 compared with that for TMC-R4. On the other hand, the high mass region peaks for both TMC spectra appeared at different $m / z$ than that for the CV spectrum. Thus, the hydrocarbon contamination was different for these samples. In the TMC-treated samples, the region was dominated by the following mass fragments: a group of signals at $m / z 368,372,382,386$, and 400 , a group at $m / z 495,523$, and a group at $m / z 551,661,638$, and 666 . 
TMC-R4 sample
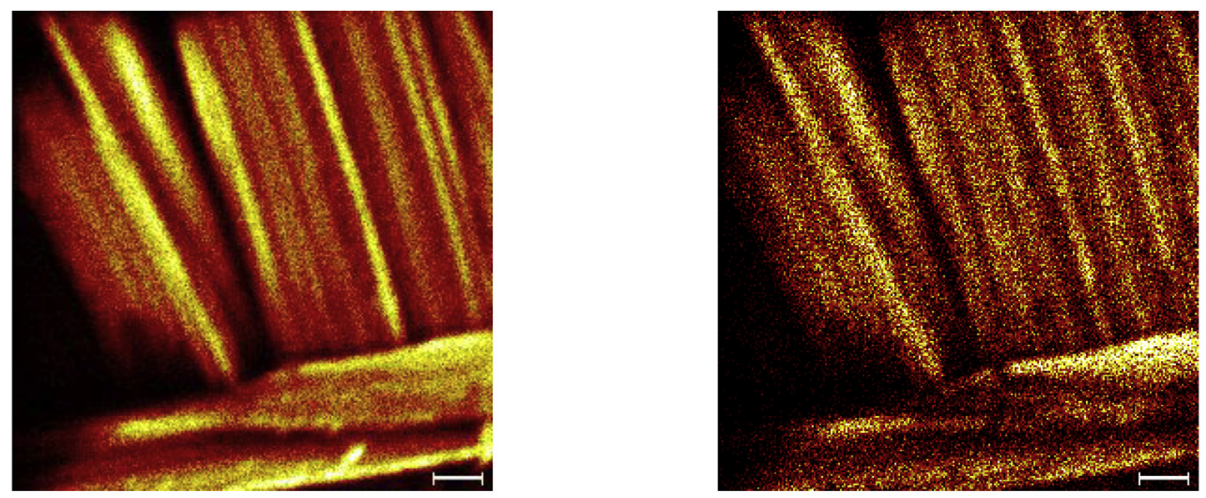

TMC-R7 sample
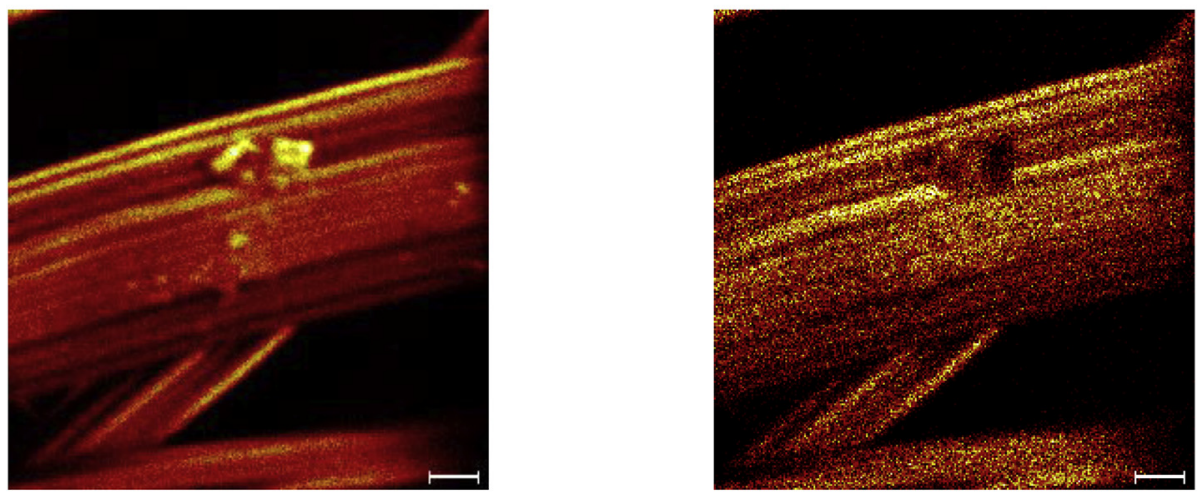

TMCNP4 sample
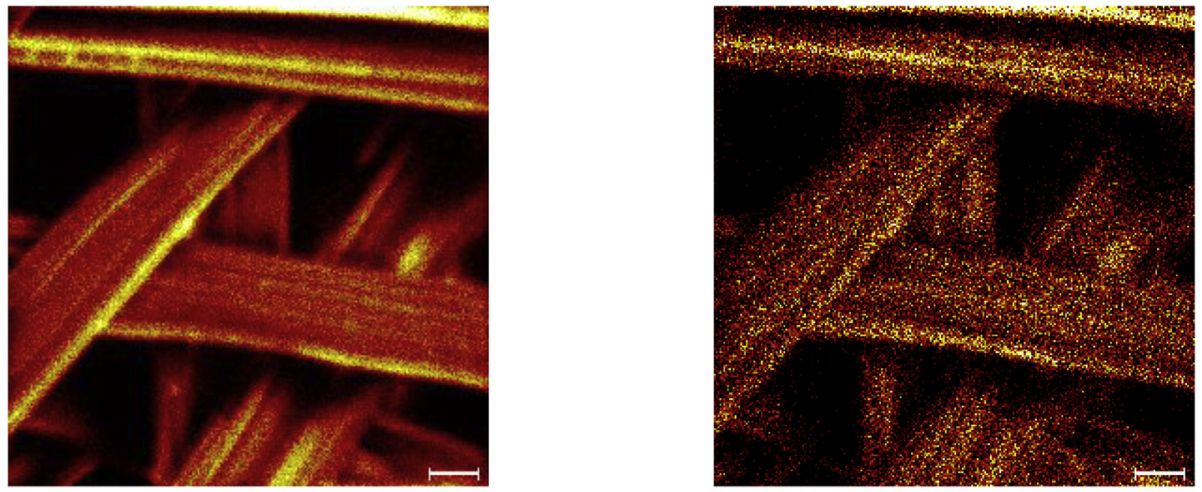

TMCNP7 sample
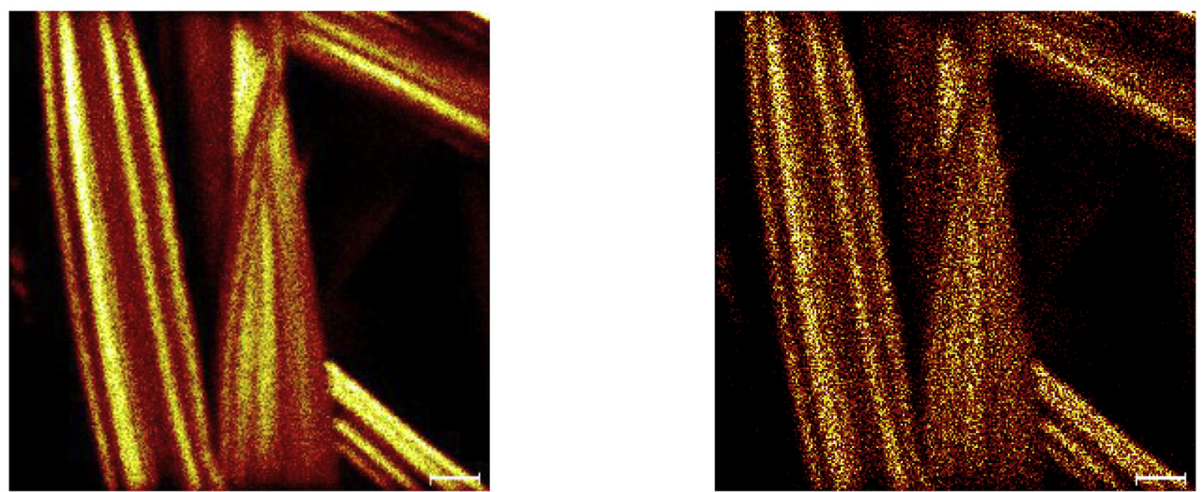


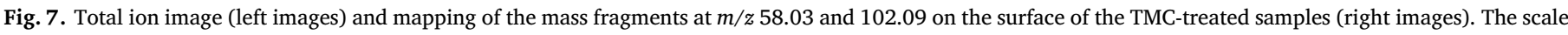
bar is $10 \mu \mathrm{m}$

\section{CSNP4 sample}

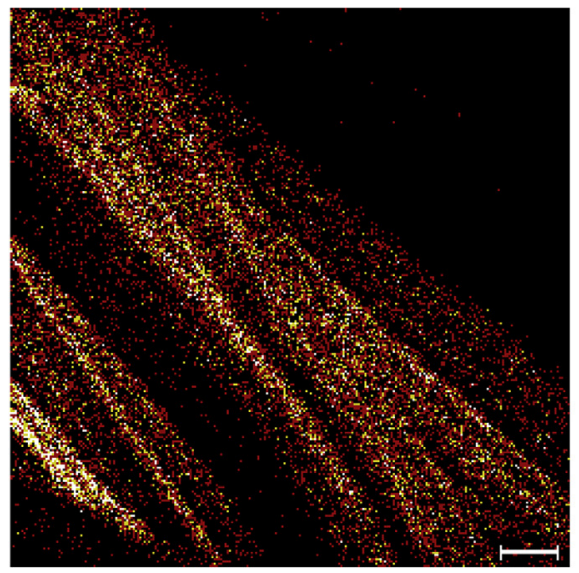

TMCNP4 sample
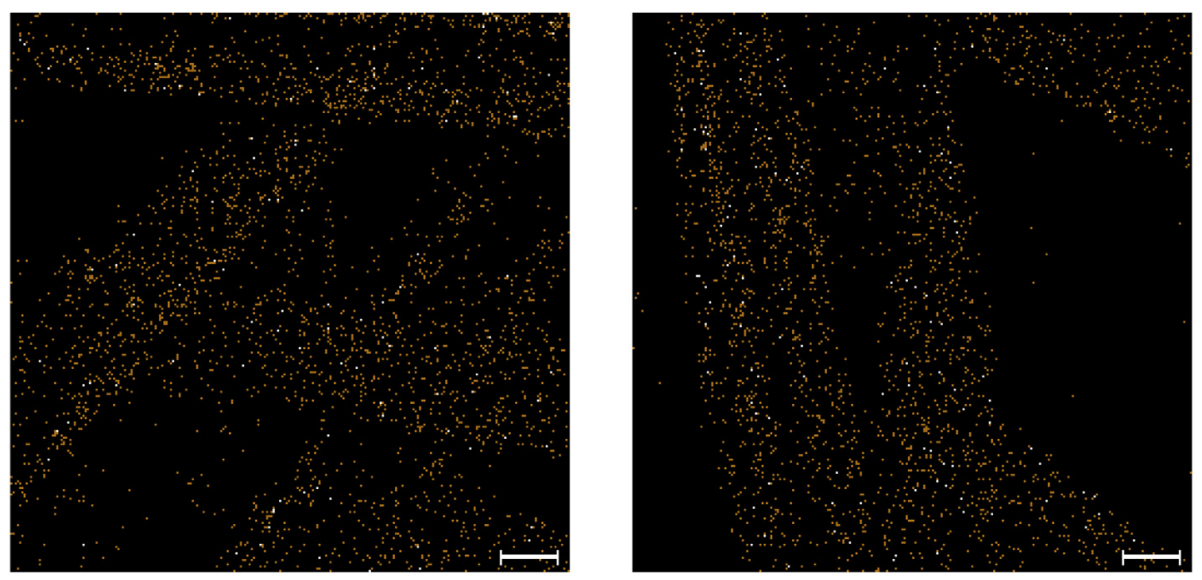

Fig. 8. ToF-SIMS mapping of $\mathrm{Na}$ at $m / z 22.99$ on the nanoparticle-treated samples. The scale bar is $10 \mu \mathrm{m}$.

\section{CSNP7 sample}

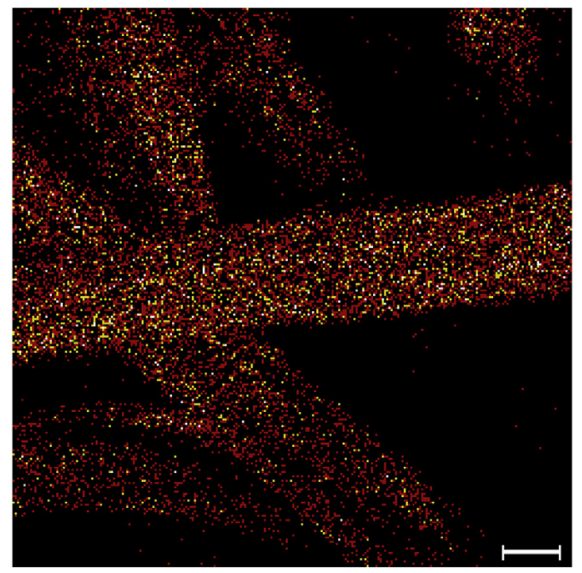

TMCNP7 sample monomer that originates from the cellulose viscous fibre in each sample.

The relative intensity ratio of the mass fragments at $\mathrm{m} / \mathrm{z} 147.90$ increased for all CS-treated samples compared with the CV reference (Table 3). This increment was most pronounced for the CS-R4 sample, suggesting that the highest amount of CS was adsorbed in that case (the highest among the CS and CSNP samples). In the case of the TMC and TMCNP samples, the trend in the amount of CS is TMCNP7 > TMCR7 > TMC-R4 > TMCNP4. For the latter, both mass peaks, at $m / z$ 58.03 and 102.09 , resulted in the same intensity ratio trend. The standard deviations given in Table 3 should also be taken into account, which were the highest for the TMCNP7 sample, indicating the most non-homogeneous distribution of CS on the surface. Therefore, the latter makes the CS concentration trend reported as TMCNP7 > TMCR7 > TMC-R4 > TMCNP4 less certain.

\section{ToF-SIMS imaging}

The surface distribution of CS was investigated by ToF-SIMS imaging. In the ToF-SIMS images, lighter pixels in the figure represent higher intensity - i.e. a higher intensity of signals in that spot. The signal intensity depends on the type of compound, how easily it 
fragments into ions, the amount of the compound on the surface, and also the topography (secondary ions escape more easily from higher regions of the sample).

In Fig. 6, the surface topography is shown by means of the total ion image, wherein the entire mass spectrum for each pixel is included, and is employed for comparison with the fragment image. The characteristic signals for mass fragments that are indicative of CS (explained above) were mapped at $m / z$ 147.90, 207.07, and 221.09 (Fig. 6). The signal intensities were relatively low for the CS-R7 sample, and especially for the nanoparticle-treated samples (CSNP), as clearly seen in Fig. 6. This again confirms the above statement that when comparing this set of samples, the highest amount of CS was adsorbed in the case of CS-R4 (as reported in Table 3).

Fig. 7 shows the surface distribution of TMC, which is represented by mapping the mass peaks at $m / z 58.03$ and 102.09 (as explained above). For the TMC-R7 sample, a particle can be seen in the total ion image, whereas this signal is missing in the fragment imaging, thus indicating that this particle was not covered with TMC.

As the presence of an Na signal $(m / z 22.99)$ indicates the presence of nanoparticles on the surface, the distribution of Na was mapped on the nanoparticle-treated samples, both CSNP and TMCNP. These maps are shown in Fig. 8. The images were constructed from the same measurements as in Figs. 6 and 7, where the total ion distributions were shown.

\section{Conclusions}

In this work, time-of-flight secondary ion mass spectrometry (ToFSIMS) was employed to show the ability of this surface-sensitive technique to systematically study different viscose fibres treated with different solutions containing various forms of chitosan. The use of this technique provided new insights in this field of research.

Characteristic signals ascribed to viscose fibre surface contamination were explained. They most likely originate from the industrial preparation procedure. These signals were detected for all samples tested, including the untreated sample. Moreover, it was also found that these signals decreased for the viscose fibre treatment in more acidic solution with $\mathrm{pH} 4$ compared to the samples prepared at neutral $\mathrm{pH} 7$, the reason being that the more acidic solution removes more contaminants from the surface.

Characteristic signals for chitosan were detected at $m / z 147.90$, 207.07, and 221.09 originating from acetylglucosamine fragments for the samples treated in the chitosan solution. These peaks were more intense for the samples prepared at $\mathrm{pH} 4$ compared with $\mathrm{pH}$ 7. On the other hand, fragments of glucosamine or chitin were not identified in the SIMS spectra. Some differences were also observed in the SIMS spectra for the viscose fibre treated in the chitosan solution and for the chitosan nanoparticle samples.

In the trimethyl chitosan-treated samples, the high mass region differed from the chitosan-treated samples and the untreated reference sample, which suggested that long-chain nitrogen-containing polymer was adsorbed that was different from the high-molecular mass hydrocarbon (contamination) detected on the untreated reference and in the chitosan-treated samples. Trimethyl chitosan was detected on the samples treated with a solution thereof. The characteristic peaks describing trimethyl chitosan on the surface were at $\mathrm{m} / \mathrm{z} 58.03$ and 102.09 .

Finally, imaging of the sample surfaces was performed using the mass peaks at $m / z 147.90,207.07$, and 221.09 for mapping the chitosan-treated samples, and the mass peaks at $m / z 58.03$ and 102.09 for mapping the trimethyl chitosan-treated samples. Mapping of the nanoparticles was performed at $m / z 23$, thus describing an Na signal that was involved in nanoparticle synthesis. This methodology enabled a clear visualisation of the different species on the solid surface and topography analysis.

\section{Acknowledgements}

The authors would like to acknowledge the financial support for this project received from the Slovenian Research Agency (Grant Number P2-0032 and J1-9169).

\section{References}

[1] S. Strnad, O. Šauper, A. Jazbec, K. Stana-Kleinschek, Influence of chemical modification on sorption and mechanical properties of cotton fibers treated with chitosan, Textil. Res. J. 78 (2008) 390-398.

[2] M.N.V. Ravi Kumar, A review of chitin and chitosan applications, React. Funct Polym. 46 (2000) 1-27.

[3] D. Elieh-Ali-Komi, M.R. Hamblin, Chitin and chitosan: production and application of versatile biomedical nanomaterials, Int. J. Adv. Res. 4 (2016) 411-427.

[4] K.P.C. Minbiole, M.C. Jennings, L.E. Ator, J.W. Black, M.C. Grenier, J.E. LaDow, K.L. Caran, K. Seifert, W.M. Wuest, From antimicrobial activity to mechanism of resistance: the multifaceted role of simple quaternary ammonium compounds in bacterial eradication, Tetrahedron 72 (2016) 3559-3566.

[5] R. Ahvenainen, 1-Introduction, in: R. Ahvenainen (Ed.), Novel Food Packaging Techniques, Woodhead Publishing, 2003, pp. 1-2.

[6] E. Shalaby, Biological Activities and Application of Marine Polysaccharides, Intech Open, 2007.

[7] T. Ristić, A. Zabret, L.F. Zemljič, Z. Peršin, Chitosan nanoparticles as a potential drug delivery system attached to viscose cellulose fibers, Cellulose 24 (2017) 739-753.

[8] L.F. Zemljič, Z. Peršin, O. Šauperl, A. Rudolf, M. Kostić, Medical textiles based on viscose rayon fabrics coated with chitosan-encapsulated iodine: antibacterial and antioxidant properties, Textil. Res. J. (2017) 0040517517725117 http://journals. sagepub.com/doi/abs/10.1177/0040517517725117\#.

[9] K.J. Chu, P.C. Chen, Y.W. You, H.Y. Chang, W.L. Kao, Y.H. Chu, C.Y. Wu, J.J. Shyue, Integration of paper-based microarray and time-of-flight secondary ion mass spec trometry (ToF-SIMS) for parallel detection and quantification of molecules in multiple samples automatically, Anal. Chim. Acta 1005 (16 April 2018) 61-69.

[10] A.C. Crecelius, J. Vitz, U.S. Schubert, Mass spectrometric imaging of synthetic polymers, Anal. Chim. Acta 808 (2014) 10-17.

[11] B. Garg, S.L. Lei, S.C. Liu, T. Bisht, J.Y. Liu, Y.C. Ling, Rapid identification of trimethyl and triethyl amines using sulphonic acidic ionic liquids: a time-of-flight secondary ion mass spectrometry study of fragmentation reactions, Anal. Chim. Acta 757 (2012) 48-55.

[12] L. Cai, L. Sheng, M. Xia, Z. Li, S. Zhang, X. Zhang, H. Chen, Graphene oxide as a novel evenly continuous phase matrix for TOF-SIMS, J. Am. Soc. Mass Spectrom. 28 (2017) 399-408.

[13] N.J. Popczun, L. Breuer, A. Wucher, N. Winograd, On the SIMS ionization probability of organic molecules, J. Am. Soc. Mass Spectrom. 28 (2017) 1182-1191.

[14] C. Poleunis, V. Cristaudo, A. Delcorte, Temperature dependence of $\mathrm{Ar}_{\mathrm{n}}+$ Cluster backscattering from polymer surfaces: a new method to determine the surface glass transition temperature, J. Am. Soc. Mass Spectrom. 29 (2018) 4-7.

[15] H.Y. Liao, J.H. Chen, J.J. Shyue, C.T. Shun, H.W. Chen, S.W. Liao, C.K. Hong, P.S. Chen, Rapid label-free determination of ketamine in whole blood using secondary ion mass spectrometry, Talanta 143 (2015) 50-55.

[16] J. Kokesch-Himmelreich, B. Woltmann, B. Torger, M. Rohnke, S. Arnhold, U. Hempel, M. Müller, J. Janek, Detection of organic nanoparticles in human bone marrow-derived stromal cells using ToF-SIMS and PCA, Anal. Bioanal. Chem. 407 (2015) 4555-4565.

[17] S. Aoyagi, K. Abe, T. Yamagishi, H. Iwai, S. Yamaguchi, T. Sunohara, Evaluation of blood adsorption onto dialysis membranes by time-of-flight secondary ion mass spectrometry and near-field infrared microscopy, Anal. Bioanal. Chem. 409 (2017) 6387-6396.

[18] M. Urbini, V. Petito, F. de Notaristefani, F. Scaldaferri, A. Gasbarrini, L. Tortora ToF-SIMS and principal component analysis of lipids and amino acids from inflamed and dysplastic human colonic mucosa, Anal. Bioanal. Chem. 409 (2017) 6097-6111.

[19] S. Aoyagi, T. Shimanouchi, T. Kawashima, H. Iwai, ToF-SIMS observation for evaluating the interaction between amyloid $\beta$ and lipid membranes, Anal. Bioanal. Chem. 407 (2015) 2859-2863.

[20] K. Schaepe, J. Werner, K. Glenske, T. Bartges, A. Henss, M. Rohnke, S. Wenisch, J. Janek, ToF-SIMS study of differentiation of human bone-derived stromal cells: new insights into osteoporosis, Anal. Bioanal. Chem. 409 (2017) 4425-4435.

[21] D.N. Ateacha, U. Koch, C. Engelhard, Direct analysis of alkaloids in natural: cinchona bark and commercial extracts using time-of-flight secondary ion mass spectrometry, Anal. Meth. 10 (2018) 950-958.

[22] J.G. Swales, G. Hamm, M.R. Clench, R.J.A. Goodwin, Mass spectrometry imaging and its application in pharmaceutical research and development: a concise review Int. J. Mass Spectrom. (2018), https://doi.org/10.1016/j.ijms.2018.02.007.

[23] J. Bobrowska, J. Pabijan, J. Wiltowska-Zuber, B.R. Jany, F. Krok, K. Awsiuk, J. Rysz, A. Budkowski, M. Lekka, Protocol of single cells preparation for time of flight secondary ion mass spectrometry, Anal. Biochem. 511 (2016) 52-60.

[24] T. Ristić, S. Hribernik, L. Fras-Zemljič, Electrokinetic properties of fibres functionalised by chitosan and chitosan nanoparticles, Cellulose 22 (2015) 3811-3823.

[25] Z. Lidija Fras, P. Zdenka, Š. Olivera, R. Andreja, K. Mirjana, Medical textiles based on viscose rayon fabrics coated with chitosan-encapsulated iodine: antibacterial and antioxidant properties, Textil. Res. J. (2017) 0040517517725117 http:// 
journals.sagepub.com/doi/abs/10.1177/0040517517725117.

[26] C. Thomson, Probing the Nature of Cellulosic Fibre Interfaces with Fluorescence Resonance Energy Transfer, Georgia Institute of Technology, Atlanta, USA, 2007.

[27] J. Schmidtbauer, Viscostar - a star-shaped Viscose Fiber for Improved Absorbency Lenzinger Berichte vol. 81, (2002), pp. 15-21.

[28] M. Finšgar, Surface analysis of 2-mercapto-1-methylimidazole adsorbed on copper by X-ray photoelectron spectroscopy, Spectrochim. Acta Mol. Biomol. Spectrosc. 190 (2018) 290-297.

[29] M. Finšgar, X-ray excited Auger Cu L3L4,5M4,5 spectra measured at low take-off angles as a fingerprint for a Cu-organics connection, J. Electron. Spectrosc. Relat. Phenom. 222 (January 2018) 10-14.

[30] P. Lopez-Perez, R. da Silva, C. Serra, I. Pashkuleva, R. Reis, Surface phosphorylation of chitosan significantly improves osteoblast cell viability, attachment and proliferation, J. Mater. Chem. (2010) 483-491.

[31] A. Grenha, B. Seijo, C. Serra, C. Remunan-Lopez, Chitosan nanoparticle-loaded mannitol microspheres: structure and surface characterization, Biomacromolecules 8 (2007) 2072-2079.
[32] S. Al-Qadi, A. Grenha, C. Remuñán-López, Microspheres loaded with polysaccharide nanoparticles for pulmonary delivery: preparation, structure and surface analysis, Carbohydr. Polym. 86 (2011) 25-34.

[33] S. Rodrigues, A. Rosa da Costa, A. Grenha, Chitosan/carrageenan nanoparticles: effect of cross-linking with tripolyphosphate and charge ratios, Carbohydr. Polym. 89 (2012) 282-289.

[34] https://massbank.eu/MassBank/jsp/RecordDisplay.jsp?id = KO002994\&dsn = Keio, H.H. Kakazu Y, Institute for Advanced Biosciences, Keio Univ., D-(+)-Glucosamine; LC-ESI-QQ; MS2; CE:10 V; [M + H] +, 2016.

[35] M.A. Olofsson, D. Bylund, Liquid chromatography with electrospray ionization and tandem mass spectrometry applied in the quantitative analysis of chitin-derived glucosamine for a rapid estimation of fungal biomass in soil, Int. J. Anal. Chem. (2016) 82016.

[36] P. Fardim, N. Duran, Modification of fibre surfaces during pulping and refining as analysed by SEM, XPS and ToF-SIMS, Colloid. Surface. Physicochem. Eng. Aspect. 223 (2003) 263-276. 